\title{
HIGH RESOLUTION SPECTRA OF M AND C STARS \\ BY FOURIER TRANSFORM SPECTROSCOPY
}

\author{
J. P. MAILLARD \\ Laboratoire Aimé Cotton, C.N.R.S. II, Orsay, France
}

A Michelson interferometer was put into operation during the year 1972 at the Coudé focus of the Haute-Provence Observatory's 76-in. telescope. We built this instrument at Aimé Cotton Laboratory (Orsay-France) where the method of Fourier Transform Spectroscopy has been largely developed in the direction of very high resolution work. A complete description of this device has been given elsewhere (Guelachvili and Maillard, 1970) and further details on the present study are reported by Maillard (1973). We will only describe the main characteristic elements of the interferometer (Figure 1).

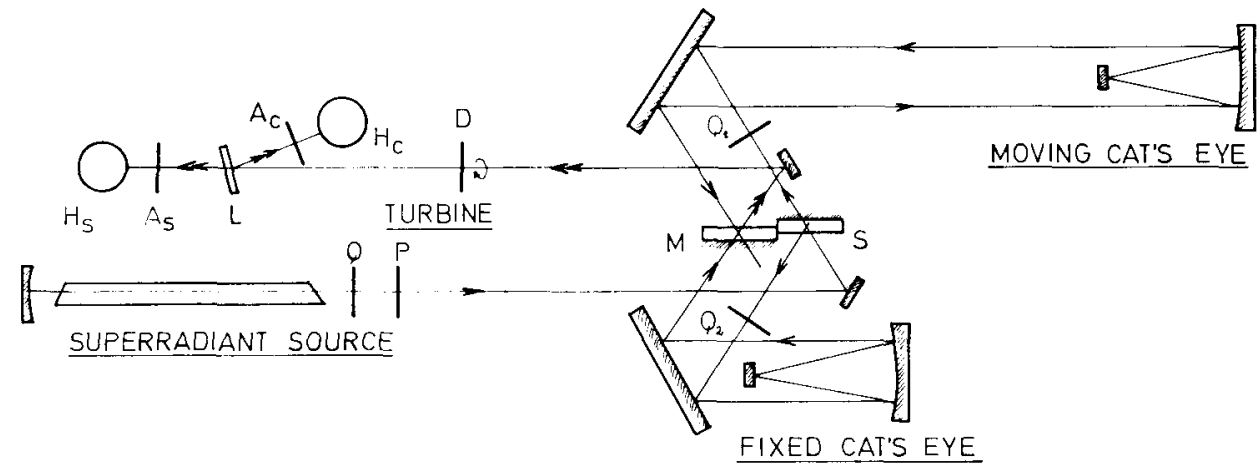

Fig. 1. Optical system of the interferometer showing the light path of the reference beam (xenon superradiant source at $3.5 \mu$ ). The path difference is measured by phase modulation system whose optical elements are: $P$, polarizer; $Q_{1}, Q_{2}$, quarter-wave plates; $D$, half-wave plate rotating at high speed; $A_{s}, A_{c}$, crossed analyzers; $H_{s}, H_{c}$, detectors.

\section{Experimental}

Because it was originally devoted to laboratory work, the maximum path-difference is two meters. The beam has a diameter of $80 \mathrm{~mm}$. It is equipped with two cat's eyes which provide two output beams. They are focused on two (dry-ice-acetone) cooled $\mathrm{PbS}$ detectors of minimum area. The path difference is interferometrically measured by means of a very sharp and stable line produced by the superradiant effect in xenon at $3.5 \mu$. This beam is small in diameter and uses the central portion of the beam of the source under study. The error signal is generated by a phase modulation system to be insensitive to the intensity fluctuations of the reference source. The interferogram is recorded by a stepping technique. So, the cycle of the operations is the following: (a) positioning, (b) modulation of the signal, (c) integration, (d) storage on 
magnetic tape in six BCD characters, (e) displacement. The modulation is performed by a square wave modulation of the path difference. This technique has been demonstrated to be very more effective in action, cancelling the large amount of noise produced by atmosphere turbulence in the interferogram (Connes et al., 1967). During all these operations the path difference is continually servo-controlled, which gives a very reliable instrument.

\section{Diagram Magnitude / Resolving Power}

This important effort to make available a high resolution instrument was justified because high resolution spectra of astronomical sources in the infrared are urgently

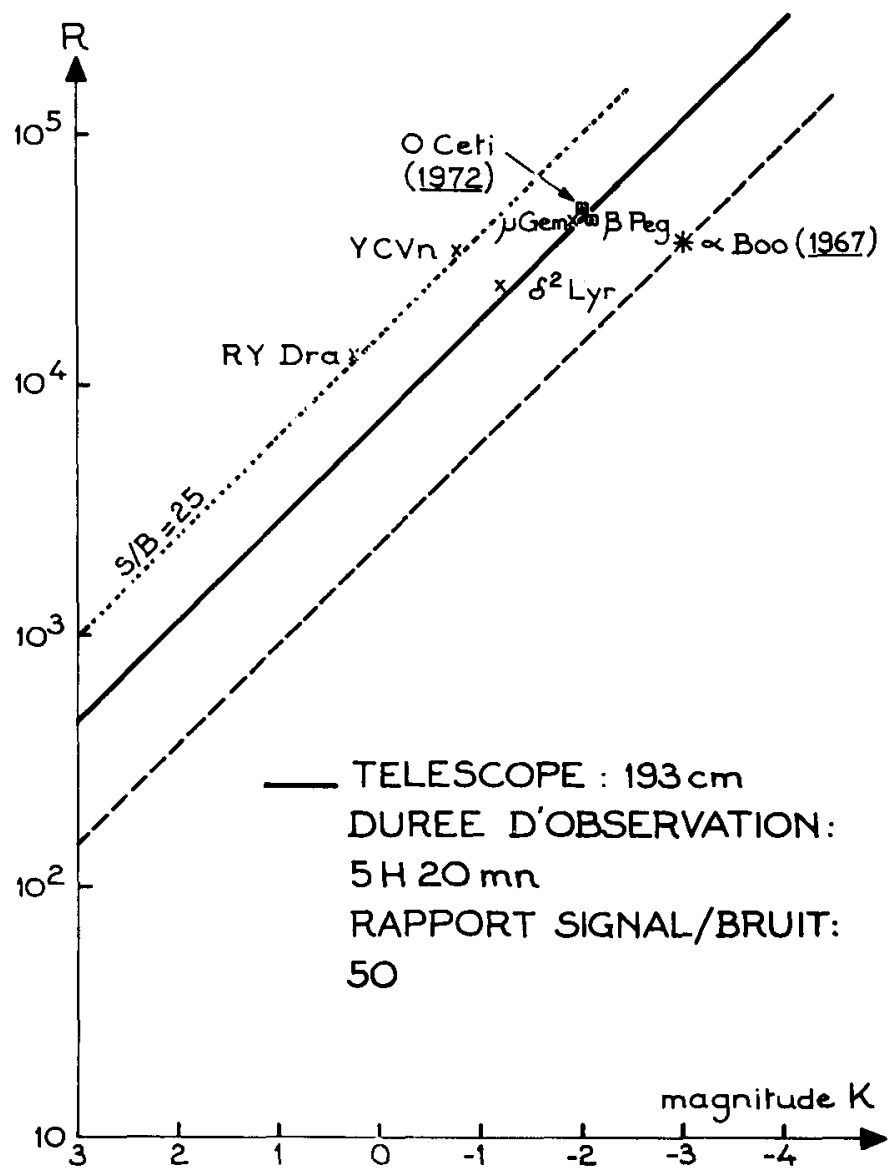

Fig. 2. Resolving power at $2 \mu$ of spectra obtained with an interferometer as a function of the $K$ magnitude of the stars, for given observational conditions. The resolution is limited by the incident energy. Full line: present interferometer (1972); dotted line: for the same instrument, with a signalto-noise ratio of 25; dashed line: comparison with a previous instrument (1967) for $S / N=50$.

Experimental points from recorded spectra are reported in the diagram. 
required, and the spectra must be of sufficient quality to permit accurate and unambiguous analysis.

The more suitable sources for high resolution work in the 1-2.5 $\mu$ range are cool stars. So, within two periods of observation, I have used this instrument in a program devoted to the study of several stars of $M$ and $C$ type.

The majority of the previous observations of these stars in this spectral range was at relatively low or middle resolution, from classical slit-spectrometers or from commercial interferometers, the more recent limit being $0.5 \mathrm{~cm}^{-1}$ (Mertz, 1972). Apart from that, a previous interferometer (Connes et al., 1967), less sophisticated than this new one, built in the same laboratory, was operating in the years 1966-67. It had produced the first high resolution spectra but of a small number of bright cool stars (Chauville et al., 1970). Compared to this original instrument we have obtained a gain in available resolving power. That can be more explained by considering the diagram of the Figure 2. The $K$ magnitudes $(M)$ are plotted on the $x$-axis (a similar diagram is possible with other infrared magnitudes), the log of the resolving power $(R)$ at $2 \mu$ on the $y$-axis. For a given telescope, the same time of observation and the same signal-tonoise ratio, all the points in this diagram are on a straight line, according to the formula*:

$$
\log R=-\frac{M}{2.5}+\text { const } .
$$

A dashed line is plotted from a result obtained on $\alpha$ Boo in 1967, with the first interferometer, and the following observational conditions-telescope size: $193 \mathrm{~cm}$; time of observation: $5^{\mathrm{h}} 20^{\mathrm{m}}$; signal-to-noise ratio: 50 . With the same conditions, all the stellar points are raised by a factor 3 from our new results. If a signal-to-noise ratio of 25 is accepted, an upper line can be plotted.

This gain is due to the improvement of the stepping system, to the reduction of transmission losses and most importantly to the use of carefully selected detectors.

It must be noted also that this diagram can have an important use before observations. The resolving power achievable on a source of given $K$ magnitude can be predicted and/or the best experimental conditions deduced.

* The signal-to-noise ratio in an absorption spectrum obtained by Fourier Transform Spectroscopy is expressed by:

$$
\frac{S}{N}=\frac{I \mathrm{~d} \sigma}{p} \sqrt{ } T
$$

with $I$, the mean energy of the source in the recorded spectral range $\left(\mathrm{W} \mathrm{cm}^{-1}\right)$; $d \sigma$, the limit of resolution $\left(\mathrm{cm}^{-1}\right) ; T$, the total observing time $(\mathrm{s}) ; P$, the noise-equivalent-power of the detectors $\left(\mathrm{W} \mathrm{Hz}^{-1 / 2}\right)$.

The resolving power $R=\sigma / \mathrm{d} \sigma$ is therefore proportional to the incident flux by:

$$
\log R=\log I+\text { const }
$$

It can be related to the magnitude through the usual definition, which gives:

$$
\log R=-\frac{M}{2.5}+\text { const. }
$$




\section{Observations}

Our observations of cool stars are summarized in Table I, II, III where the stars are listed with their spectral type and the luminosity class in general use, the $V$ and $K$ magnitude taken from the 'Two-Micron Sky Survey' (Neugebauer and Leighton, 1969) or from the photometric measurements of Johnson (1964), the recording time, the date of observation and the limit of resolution reached (by taking into account the apodization used). For all the presented spectra, the signal-to-noise ratio has a figure of 25 to 50 in the 1.6 and $2 \mu$ regions.

\subsection{NORMAL M STARS}

Table I gives a set of M stars of class II and III, in which spectral type goes from M0 to M6.

From these spectra, all having approximately the same resolution, a coarse analysis can be achieved, to study the evolution of the $\mathrm{C} / \mathrm{O}, \mathrm{C} / \mathrm{H},{ }^{12} \mathrm{C} /{ }^{13} \mathrm{C}$ ratios and of other parameters such as the turbulent velocity and the temperature, according to the spectral type. Other specific problems and more detailed analysis of each spectrum are also possible as will be shown on $\alpha$ Her.

TABLE I

Observational conditions of normal $\mathbf{M}$ stars

\begin{tabular}{|c|c|c|c|c|c|c|}
\hline \multirow[t]{2}{*}{ Star } & \multirow{2}{*}{$\begin{array}{l}\text { Spectral } \\
\text { type }\end{array}$} & \multicolumn{2}{|c|}{ Magnitude } & \multirow{2}{*}{$\begin{array}{l}\text { Date of } \\
\text { observation }\end{array}$} & \multirow{2}{*}{$\begin{array}{l}\text { Recording } \\
\text { time }\end{array}$} & \multirow{2}{*}{$\begin{array}{l}\text { Limit of } \\
\text { resolution } \\
\left(\mathrm{cm}^{-1}\right)\end{array}$} \\
\hline & & $\begin{array}{l}V \\
(0.55 \mu)\end{array}$ & $\begin{array}{l}K \\
(2.2 \mu)\end{array}$ & & & \\
\hline$\mu \mathrm{U}$ Maj & M0 III & 3.04 & -0.82 & 29.04 .72 & $3^{\mathrm{h}} 20^{\mathrm{m}}$ & 0.20 \\
\hline$\beta$ Peg & M2 II & 2.54 & -2.16 & 15.12 .72 & $4^{\mathrm{n}} 20^{\mathrm{m}}$ & 0.12 \\
\hline$\mu \mathrm{Gem}$ & M3 III & 2.83 & -1.89 & 15.12 .72 & $4^{\mathrm{h}} 50^{\mathrm{m}}$ & 0.11 \\
\hline$\delta^{2} \mathrm{Lyr}$ & M4 II & 4.31 & -1.21 & 06.05 .72 & $3^{\mathrm{h}} 40^{\mathrm{m}}$ & 0.24 \\
\hline$\alpha$ Her & M5 II & 3.05 & -3.44 & 23.04 .72 & $2^{\mathrm{n}} 25^{\mathrm{m}}$ & 0.12 \\
\hline & & 00 & & 04.05.72 & $3^{\text {no }} 05^{m}$ & 0.10 \\
\hline g Her & M6 III & 4.4 & -2 & 03.05 .72 & $2^{\mathrm{h}} 30^{\mathrm{m}}$ & 0.17 \\
\hline
\end{tabular}

TABLE II

Observational conditions of $\mathrm{C}$ stars

\begin{tabular}{|c|c|c|c|c|c|c|}
\hline \multirow[t]{2}{*}{ Star } & \multirow{2}{*}{$\begin{array}{l}\text { Spectral } \\
\text { type }^{a}\end{array}$} & \multicolumn{2}{|c|}{ Magnitude } & \multirow{2}{*}{$\begin{array}{l}\text { Date of } \\
\text { observation }\end{array}$} & \multirow{2}{*}{$\begin{array}{l}\text { Recording } \\
\text { time }\end{array}$} & \multirow{2}{*}{$\begin{array}{l}\text { Limit of } \\
\text { resolution } \\
\left(\mathrm{cm}^{-1}\right)\end{array}$} \\
\hline & & $V$ & $K$ & & & \\
\hline UU Aur & C5 SR & 5.3 & -0.71 & 26.04 .72 & $3^{\text {h }}$ & 0.17 \\
\hline Y CVn & SR & 4.8 & -0.77 & $\left\{\begin{array}{l}24.04 .72 \\
04.05 .72\end{array}\right.$ & $\begin{array}{l}3^{\mathrm{h}} 30^{\mathrm{m}} \\
3^{\mathrm{h}} 45^{\mathrm{m}}\end{array}$ & $\begin{array}{l}0.17 \\
0.17\end{array}$ \\
\hline RY Dra & C4 SR & 6.3 & +0.27 & 26.04 .72 & $2^{\mathrm{n}} 30^{\mathrm{m}}$ & 0.55 \\
\hline U Hya & C7 I & 4.8 & -0.67 & 07.05 .72 & $2^{\mathrm{h}} 30^{\mathrm{m}}$ & 0.55 \\
\hline
\end{tabular}

a SR: semi-regular; I: irregular. 
HIGH RESOLUTION SPECTRA OF M AND C STARS

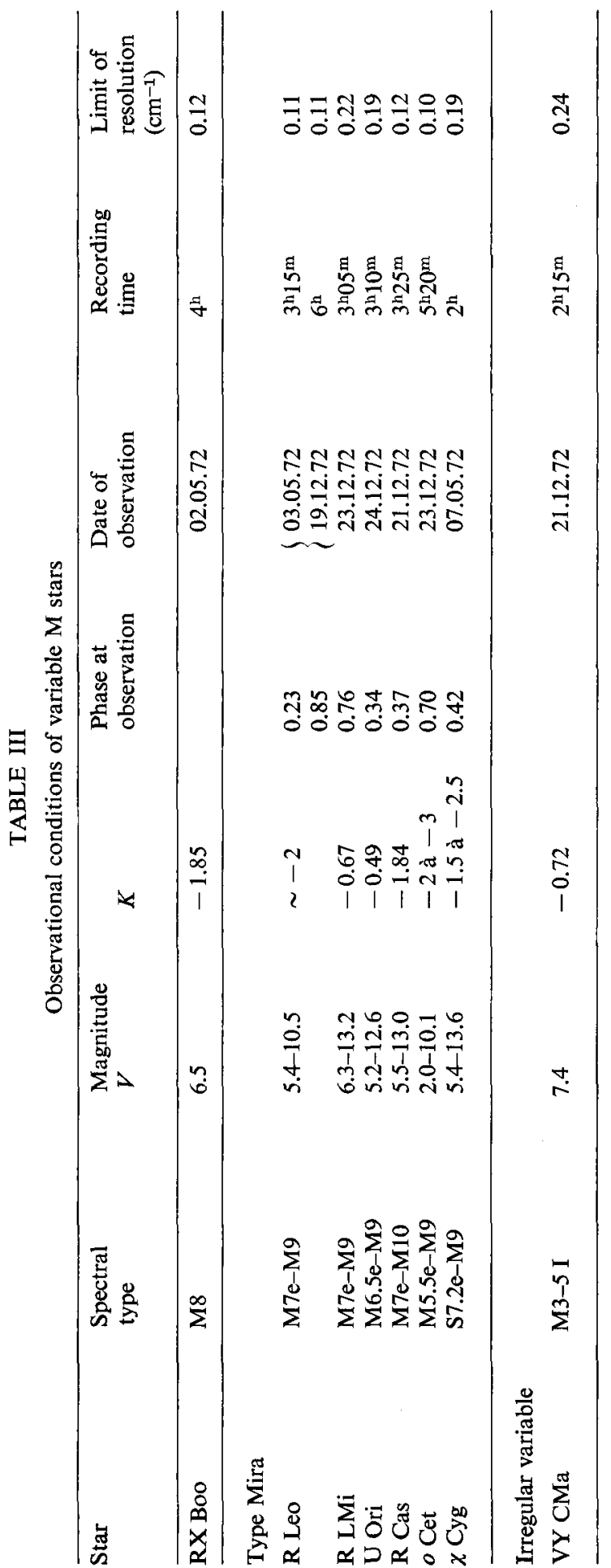




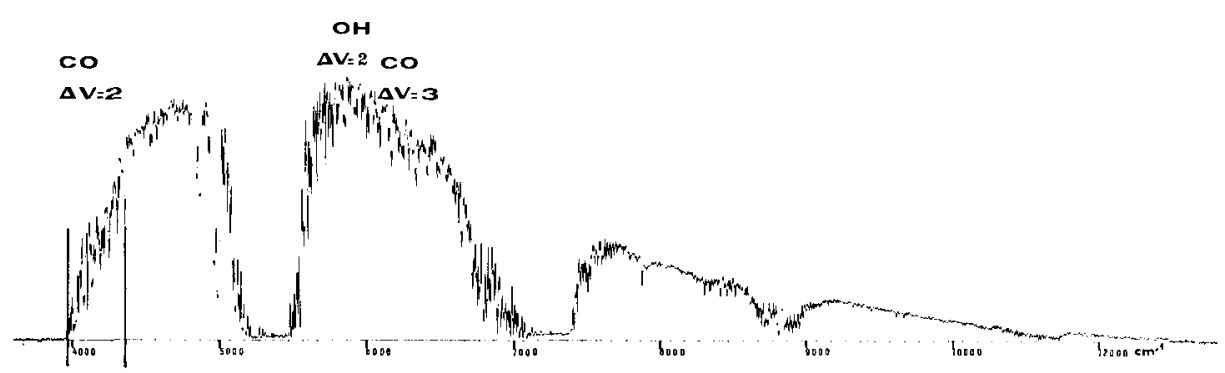

Fig. 3. Low resolution spectrum of $\alpha$ Her, computed from the 4000 first points of the high-resolution interferogram $\left(\mathrm{d} \sigma \simeq 5.5 \mathrm{~cm}^{-1}\right)$, showing the covered spectral range and the available windows, as do for all of the spectra. The region of this spectrum included between the marks has been extensively studied and is presented at high resolution in Figure 6.

Figure 3 shows the low resolution spectrum of $\alpha$ Her computed from the beginning of the interferogram. The whole spectral range is divided into windows by the strong atmospheric water vapor absorptions, as are all of our spectra. Other important features are due to telluric $\mathrm{CO}_{2}$ and $\mathrm{O}_{2}$. The general shape of the continuum is due to the decreasing sensitivity of the $\mathrm{PbS}$ detector toward the red part of the spectrum.

\subsection{VARIABLE M STARS - MIRA VARIABLES}

The variale $\mathrm{M}$ stars which have been observed are presented in Table III.

One non-Mira star of M8 type, the semi-regular variable RX Boo was observed. In addition to a particular study the data can be analysed according to the preceding program.

But among the later $M$ type stars, the Mira variables comprise an attractive class. So, I have recorded spectra of several stars of this type. Phase, computed from the Lockwood's data (Lockwood and Wing, 1971) have been specified, as well as the mean spectral type at minimum and maximum light. It would be necessary to record spectra at high resolution for different phases in the course of one cycle to account for the changes in stellar atmosphere. Two distinct observations were made during a cycle for $\mathrm{R}$ Leo. An analysis of this star is in progress and a preliminary result with regards to the structure of its atmosphere will be presented.

In addition, these spectra can provide important information on the role of $\mathrm{H}_{2} \mathrm{O}$ in connection with $\mathrm{OH}$ in these stellar atmospheres. The rotational structure of these constituents is well resolved, particularly in the $o$ Cet spectrum where they are abundant and where the highest resolution has been reached with $0.1 \mathrm{~cm}^{-1}$. High resolution is essential for analysis of these very complex spectra.

A very different, but exciting object has also been observed: the irregular variable star VY CMa. One spectrum only has been previously recorded at low resolution $\left(8 \mathrm{~cm}^{-1}\right)$ in the $\mathrm{PbS}$ region (Johnson et al., 1968). Our new spectrum has a limit of resolution of $0.24 \mathrm{~cm}^{-1}$. Figure 4 shows the low resolution spectrum of VY CMa $\left(5.5 \mathrm{~cm}^{-1}\right)$ computed from the beginning of the interferogram, which confirms the abnormal brightness at $2 \mu$ of this star, compared to a normal $\mathrm{M}$ star. 


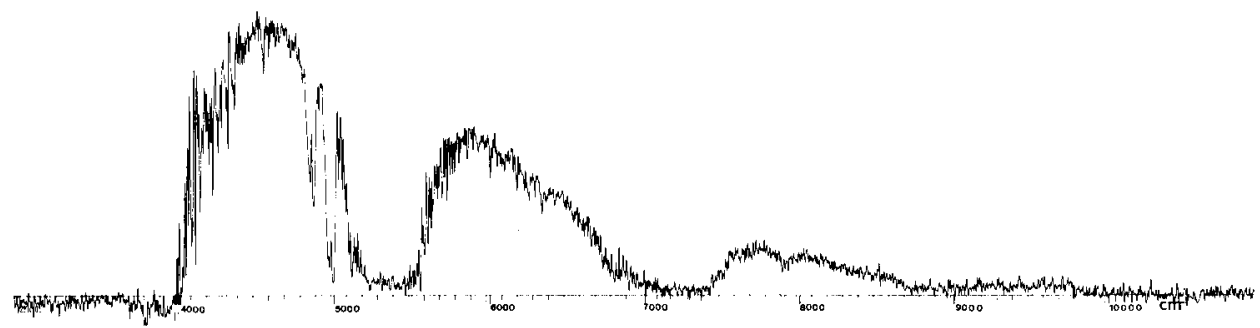

Fig. 4. Similar plot to Figure 3 for $\mathrm{VY} \mathrm{CMa,} \mathrm{showing} \mathrm{comparatively} \mathrm{the} \mathrm{abnormal}$ brightness of the $2 \mu$ window.

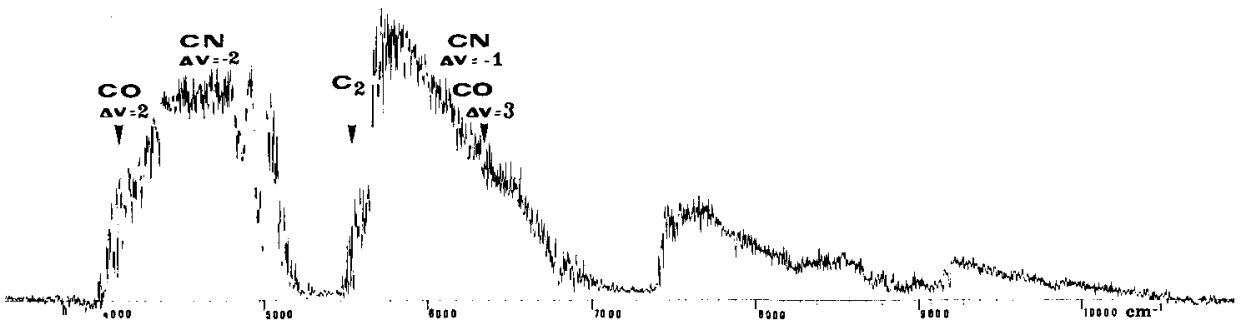

Fig. 5. Low resolution spectrum of $\mathrm{Y} C V n$ showing the location of the main stellar features.

\subsection{STARS}

The first spectroscopic observations in the $2 \mu$ region of some carbon rich stars were begun by Boyce and Sinton (1964) with a birefringent interferometer with a limit of resolution of $20 \mathrm{~cm}^{-1}$. Other low resolution interferometric spectra were recorded afterwards at $8 \mathrm{~cm}^{-1}$ (Johnson et al., 1968). Also at low resolution, (around $R=600$ ), spectra of carbon stars were scanned by using an Ebert-Fastie spectrometer, by McCammon et al. (1967) and more recently by Frogel and Hyland (1972). Only the Y CVn spectrum had been previously recorded in 1966 at about $0.8 \mathrm{~cm}^{-1}$ with the first interferometer evocated before (Connes et al., 1968).

Table II lists the observational details associated with four C Stars. The limit of resolution for UU Aur and Y CVn is $0.17 \mathrm{~cm}^{-1}$. It is slightly lower than for some $\mathrm{M}$ stars because we cannot find $\mathrm{C}$ stars as bright as $\mathrm{M}$ stars.

It must be noted that for $\mathrm{U}$ Hya a higher resolution can be reached with reference to the other results. This relatively low value is only the fact of the limited telescope time which was available.

Figure 5 gives from a low resolution spectrum the general shape of $\mathrm{Y} \mathrm{CVn} \mathrm{spectrum.}$ As it is now well-known the most important features in this spectral range are due to diatomic molecules involving carbon. $\mathrm{CO}$ is present in the first and the second overtone. $\mathrm{CN}$, particularly strong in $\mathrm{YCVn}$, extends along all the spectrum with $\Delta v=0$, $\Delta v=-1, \Delta v=-2, \Delta v=-3$ bands in an extreme overlapping. Ballik-Ramsay system of $\mathrm{C}_{2}$ gives sharp discontinuity at about $5660 \mathrm{~cm}^{-1}$.

High resolution spectra are essential for the analysis of these very complex atmo- 
spheres. Model computations and synthetic spectra to compare to these spectra are in progress by F. and M. Querci (1974).

\section{Analysis of the First Overtone of $\mathrm{CO}$ in $\alpha \mathrm{Her}$}

We now present the first results which were obtained from the analysis of a small fraction of the high resolution spectra recorded. $\alpha$ Her provides a typical example for $M$ stars.

The first high resolution spectrum of $\alpha \mathrm{Her}$ had been taken with the first interferometer in 1966, with a limit of resolution of $0.17 \mathrm{~cm}^{-1}$ in the windows $5500-7000 \mathrm{~cm}^{-1}$ and $7300-8700 \mathrm{~cm}^{-1}$. Since this date, no new spectra at similar resolution were recorded. (with all due deference to $R$. I. Thompson (Thompson et al., 1972) $0.5 \mathrm{~cm}^{-1}$ on $\alpha$ Her is not for me a high resolution!) Hence, with our interferometer we have recorded a new spectrum at $0.1 \mathrm{~cm}^{-1}$ over the range $4000-10000 \mathrm{~cm}^{-1}$ as it is presented in Figure 3. Figure 6 shows a part of the high resolution spectrum in the region of the first-overtone band sequences of $\mathrm{CO}$.

\subsection{MeTHOD OF IDENTIFICATION}

First, we have made an identification of the $\mathrm{CO}$ lines. For this purpose we have used a program computing the $\mathrm{CO}$ lines positions and the intensities, derived from Kunde's (1967) program by F. Querci and T. Tsuji. Molecular constants determined by Mantz et al. (1970) were introduced. We have plotted a synthetic spectrum with the positions of the ${ }^{12} \mathrm{CO}$ and ${ }^{13} \mathrm{CO}$ lines for the $2-0,3-1,4-2,5-3,6-4$ bands as is shown in Figure 7 to make the identification easier because $\mathrm{CO}$ bands presents very complex overlapping. This synthetic spectrum could be directly superimposed on the stellar spectrum. A comparison solar spectrum gave the telluric lines. In this way a great number of ${ }^{12} \mathrm{CO}$ and ${ }^{13} \mathrm{CO}$ lines were identified, and, the equivalent widths were measured, for the purest lines.

\subsection{Detection of ${ }^{12} \mathrm{C}^{17} \mathrm{O}$}

In spite of the innumerable lines of $\mathrm{CO}$ we have been able to detect some other lines which obviously were stellar features but not due to the most abundant isotopes of $\mathrm{CO}$. Some of them were atomic lines and we have also identified in this region the lines of the 1-0 band of HF. But also we have identified a set of lines due to an isotopic species of $\mathrm{CO}:{ }^{12} \mathrm{C}^{17} \mathrm{O}$. It is the first time that isotopic oxygen ${ }^{17} \mathrm{O}$ is clearly identified in a stellar atmosphere. To make this identification $\mathrm{I}$ have computed the ${ }^{12} \mathrm{C}^{17} \mathrm{O}$ lines positions from the preceding program by introducing ${ }^{12} \mathrm{C}^{17} \mathrm{O}$ molecular constants formed from ${ }^{12} \mathrm{C}^{16} \mathrm{O}$ constants by using expressions which relate the molecular constants of isotopes. The wavenumbers are in very good agreement for 13 lines of the $R$ branch 2-0 band as it is shown in Table IV. The rms value of the error for each line between the observed and the computed positions is $0.015 \mathrm{~cm}^{-1}$. All other predicted lines are either blended with telluric lines or more often with lines of other isotopic $\mathrm{CO}$. The $2-0$ band head of ${ }^{12} \mathrm{C}^{17} \mathrm{O}$ is confused with the $3-1$ band head of ${ }^{12} \mathrm{C}^{16} \mathrm{O}$. Figure 8 shows the ${ }^{12} \mathrm{C}^{17} \mathrm{O}$ identified lines. 


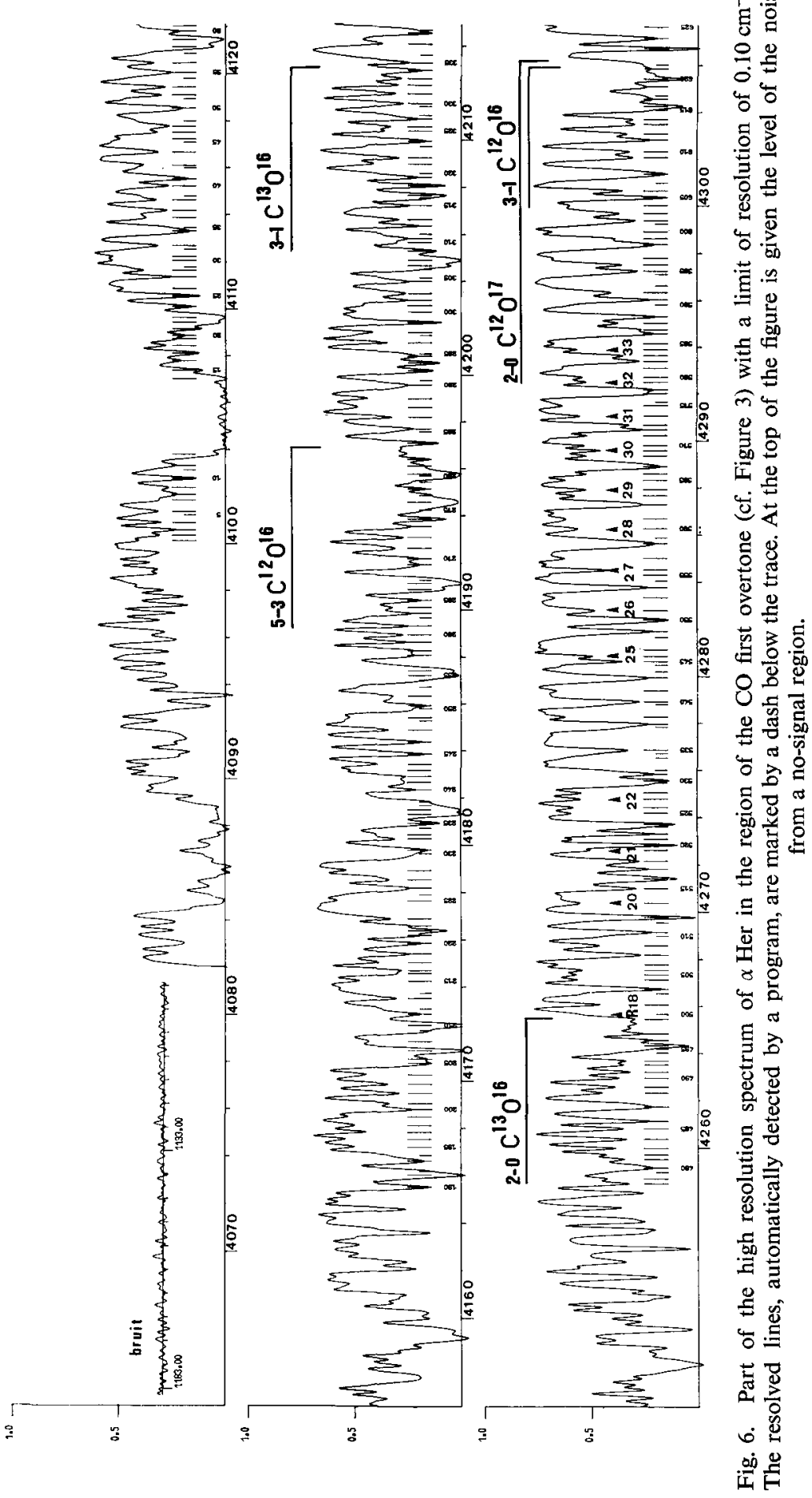




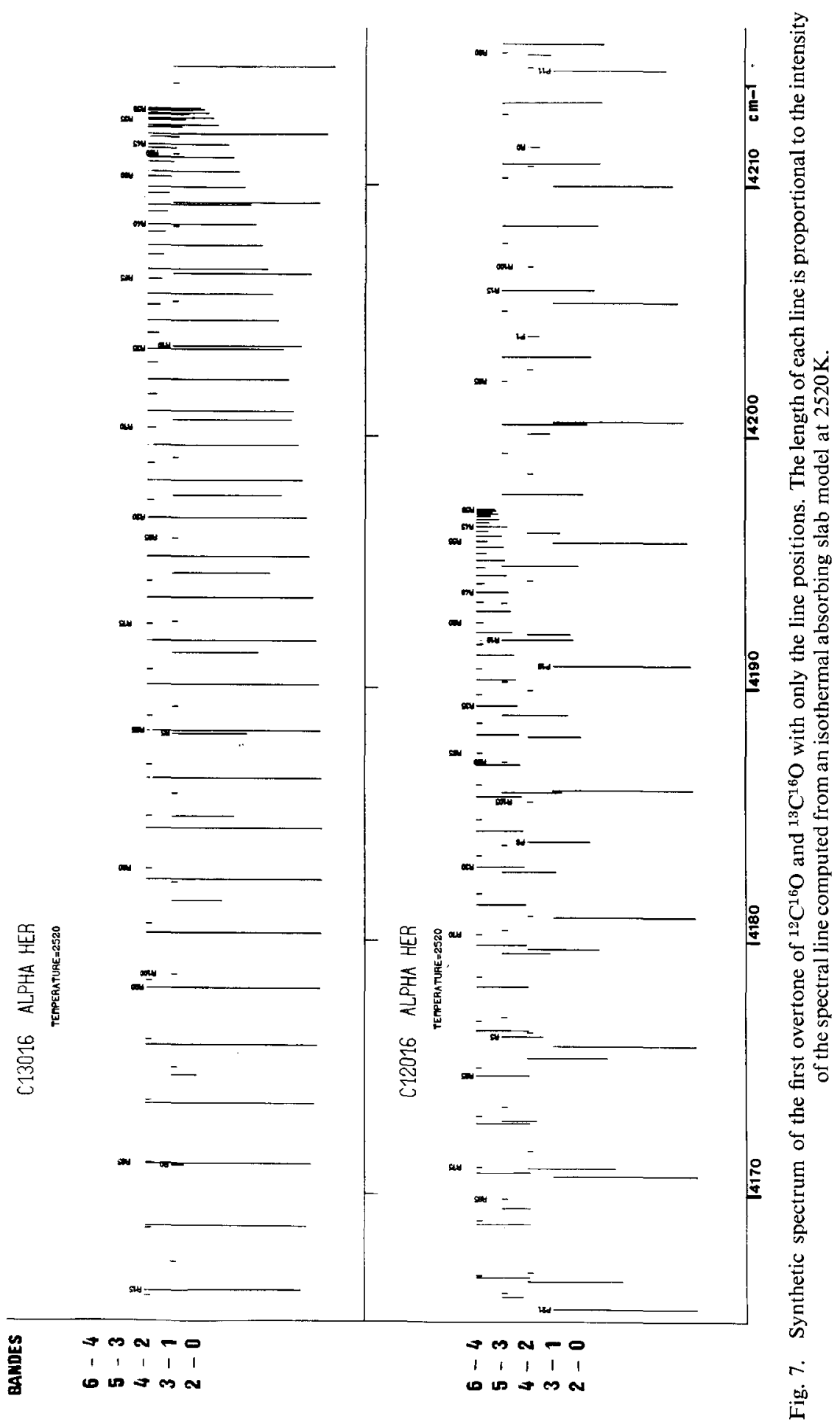




\section{TABLE IV}

Positions of ${ }^{12} \mathrm{C}^{17} \mathrm{O}$ identified lines in $\alpha$ Her after correction of the shift due to the radial velocity of the star, compared to the computed values and measurements of the equivalent width

\begin{tabular}{|c|c|c|c|c|c|}
\hline$J$ & $\begin{array}{l}\sigma \text { calculated } \\
\left(\mathrm{cm}^{-1}\right)\end{array}$ & $\begin{array}{l}\sigma \text { observed } \\
\text { (after corr. VR) } \\
\left(\mathrm{cm}^{-1}\right)\end{array}$ & $\begin{array}{l}\sigma_{\text {obs. }}-\sigma_{\text {cal }} . \\
\left(\mathrm{cm}^{-1}\right)\end{array}$ & Remarks & $\begin{array}{l}\text { Equiv. } \\
\text { width } \\
\left.\text { ( } W \mathrm{~cm}^{-1}\right)\end{array}$ \\
\hline 3 & 4221.095 & 4221.120 & +0.025 & $\begin{array}{l}\text { Blend sans doute avec } \\
\text { autre raie }\end{array}$ & 0.091 \\
\hline 4 & 4224.504 & 4224.498 & -0.006 & & 0.055 \\
\hline 5 & 4227.846 & & & & \\
\hline 6 & 4231.119 & & & & \\
\hline 7 & 4234.324 & & & & \\
\hline 8 & 4237.461 & & & & \\
\hline 9 & 4240.529 & & & & \\
\hline 10 & 4243.528 & & & & \\
\hline 11 & 4246.458 & & & Tête de la bande $4-2$ de & \\
\hline 12 & $\begin{array}{l}4249.319 \\
4252.111\end{array}$ & 4250.886 & & $\begin{array}{l}\mathrm{C}^{12} \mathrm{O}^{16} \\
\end{array}$ & \\
\hline 13 & & & & & \\
\hline $\begin{array}{l}14 \\
15\end{array}$ & & & & & \\
\hline 16 & 4260.070 & & & & \\
\hline 17 & 4262.584 & & & & \\
\hline 18 & 4265.028 & 4264.993 & -0.035 & $\begin{array}{l}\text { tête de la bande } 2-0 \text { de } \\
\mathrm{C}^{13} \mathrm{O}^{16} \text { à gauche }\end{array}$ & \\
\hline 19 & 4267.402 & 4267.518 & & $+R 1(2-0) \mathrm{C}^{12} \mathrm{O}^{16}$ & \\
\hline 20 & 4269.706 & 4269.701 & -0.005 & & 0.090 \\
\hline 21 & 4271.939 & 4271.944 & +0.005 & raie $\delta s$ à droite & 0.090 \\
\hline 22 & 4274.102 & 4274.109 & +0.007 & & 0.060 \\
\hline 23 & 4276.195 & 4276.170 & & + doublet de $\mathrm{Na}$ I & \\
\hline 24 & 4278.217 & 4278.243 & & $+R 4(2-0) \mathrm{C}^{12} \mathrm{O}^{16}$ & \\
\hline 25 & 4280.168 & 4280.183 & +0.015 & raie $*$ m à gauche & 0.061 \\
\hline 26 & 4282.048 & 4282.115 & & $\begin{array}{l}\text { + raie } \delta \mathrm{m}, R 5(2-0) \\
\mathrm{C}^{12} \mathrm{O}^{16} \text { à gauche }\end{array}$ & \\
\hline 27 & 4283.857 & 4283.846 & -0.011 & + raie $\delta f$ & 0.095 \\
\hline 28 & 4285.595 & 4285.586 & -0.009 & & 0.082 \\
\hline 29 & 4287.261 & 4287.246 & -0.015 & & 0.078 \\
\hline 30 & 4288.856 & 4288.915 & & t-raie $\delta \mathrm{m}$ & \\
\hline 31 & 4290.379 & 4290.386 & +0.007 & & 0.072 \\
\hline 32 & 4291.830 & 4291.841 & +0.011 & $\begin{array}{l}\mathrm{R} 8(2-0) \mathrm{C}^{12} \mathrm{O}^{16} \text { à } \mathrm{g} . \\
R 92(2-0) \mathrm{C}^{12} \mathrm{O}^{16} \text { à d. }\end{array}$ & 0.070 \\
\hline $\begin{array}{l}33 \\
34\end{array}$ & 4293.209 & 4293.235 & +0.026 & $R 68(3-1) \mathrm{C}^{12} \mathrm{O}^{16}$ à $\mathrm{g}$. & \\
\hline 50 & 4305.521 & & & Tête de la bande $3-1$ de & \\
\hline 51 & 4305.582 & 4305.367 & & $\mathrm{C}^{12} \mathrm{O}^{16}+$ tête de la bande & \\
\hline 52 & 4305.569 & & & $2-0 \mathrm{de} \mathrm{C}^{12} \mathrm{O}^{17}$ & \\
\hline 53 & 4305.481 & & & & \\
\hline
\end{tabular}

In the column 'Remarks' are given the lines blending the ${ }^{12} \mathrm{C}^{17} \mathrm{O}$ lines

$\mathrm{\delta}=$ telluric line; ${ }^{*}=$ stellar line.

$\mathbf{s}=$ strong, $\mathrm{m}=$ medium, $\mathrm{f}=$ faint.

à droite (at right) $=$ line bluer than the considered line.

à gauche $($ at left $)=$ line redder than the considered line . 


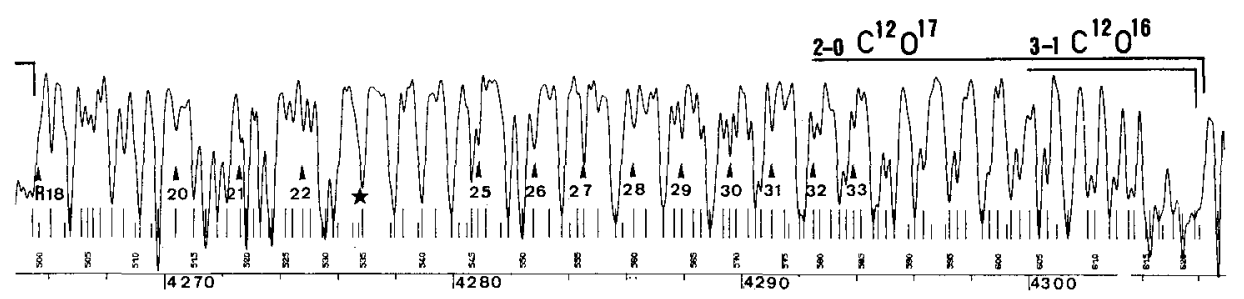

Fig. 8. Part of $\alpha$ Her spectrum showing, among the lines due to ${ }^{12} \mathrm{C}^{16} \mathrm{O}$, some identified lines of the $R 2-0$ branch of ${ }^{12} \mathrm{C}^{17} \mathrm{O}$ (the line marked by an asterisk is a $\mathrm{Na}$ doublet).

TABLE V

Possible lines of ${ }^{12} \mathrm{C}^{18} \mathrm{O}$ with the same indication as in the previous table

\begin{tabular}{|c|c|c|c|c|c|}
\hline$J$ & $\begin{array}{l}\sigma \text { observed } \\
\left(\mathrm{cm}^{-1}\right)\end{array}$ & $\begin{array}{l}\sigma \text { calculated } \\
\left(\mathrm{cm}^{-1}\right)\end{array}$ & $\begin{array}{l}\Delta \sigma \\
\sigma_{\text {obs. }}-\sigma_{\text {cal. }} . \\
\left(\mathrm{cm}^{-1}\right)\end{array}$ & Remarks & $\begin{array}{l}\text { Equiv. } \\
\text { value } \\
\left(W \mathrm{~cm}^{-1}\right)\end{array}$ \\
\hline $\begin{array}{l}23 \\
24 \\
25 \\
26 \\
27 \\
28\end{array}$ & 4227.120 & 4227.086 & +0.034 & $P 8(2-0) \mathrm{C}^{12} \mathrm{O}^{16}$ at right & 0.050 \\
\hline $\begin{array}{l}29 \\
30\end{array}$ & 4238.138 & 4238.031 & +0.107 & $R 8(3-1) \mathrm{C}^{12} \mathrm{O}^{16}$ at right & \\
\hline 31 & 4241.182 & 4241.129 & +0.053 & $\begin{array}{l}R 9(3-1)+R 34(4-2) \mathrm{C}^{12} \mathrm{O}^{16} \\
\text { at right }\end{array}$ & \\
\hline $\begin{array}{l}32 \\
33\end{array}$ & & & & & \\
\hline 34 & 4245.163 & 4245.255 & -0.092 & $R 62(4-2) \mathrm{C}^{12} \mathrm{O}^{16}$ at left & \\
\hline
\end{tabular}

\subsection{Detection of ${ }^{12} \mathrm{C}^{18} \mathrm{O}$}

Having ${ }^{12} \mathrm{C}^{17} \mathrm{O}$ detected $\mathrm{I}$ have carried out a search of ${ }^{12} \mathrm{C}^{18} \mathrm{O}$ by the same technique. But the discovery is less clear because in the ${ }^{12} \mathrm{C}^{18} \mathrm{O}$ region the mixing of the bands of other isotopic $\mathrm{CO}$ species, largely stronger than ${ }^{12} \mathrm{C}^{18} \mathrm{O}$, is inextricable. Hence, only four lines may be possibly due to this isotopic variant. The measurements are listed in Table $\mathrm{V}$.

\subsection{Estimation OF THE ROtATIONAL TEMPERATURE OF CO}

In order to give a rough estimation of the isotopic ratios I have attempted to determine the rotational temperature of $\mathrm{CO}$. By plotting the variation of the equivalent widths with the $J$ quantum number of the $R 2-0$ branch of each isotopic species (Figure 9) it was clearly shown that the measurements cannot be described by absorption in a simple slab model at uniform temperature. Weakest lines (around $J=90$ ) fall on a curve-of-growth giving $T \simeq 6500 \mathrm{~K}$. This high temperature is likely attributable to a significant temperature gradient in the atmosphere. The strongest lines can define a mean apparent excitation temperature of the $\mathrm{CO}$ layer. By plotting the 


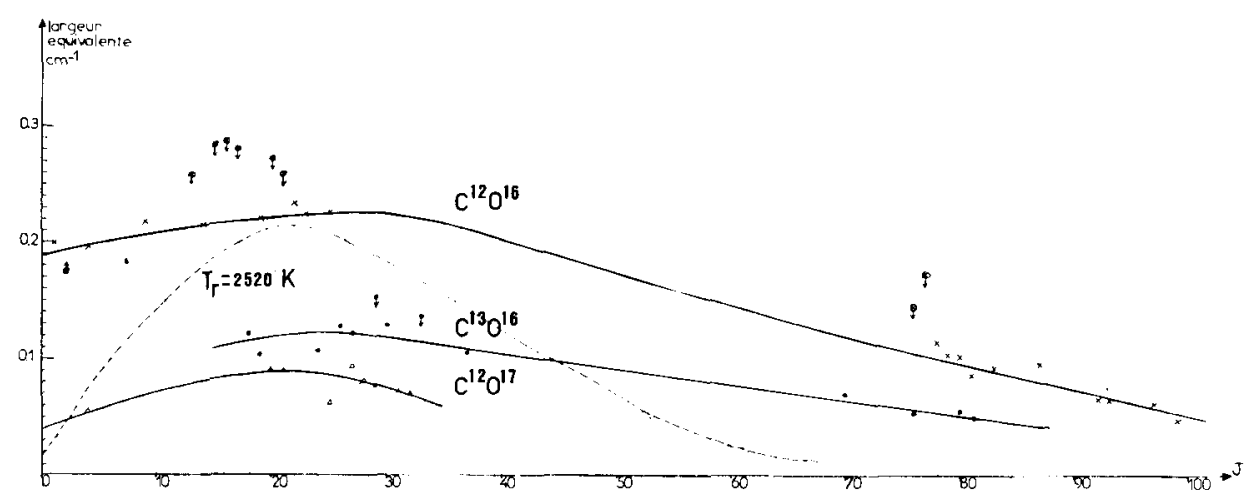

Fig. 9. Variation of the equivalent widths with the $J$ quantum number for the $R 2-0$ branch of each isotopic species of $\mathrm{CO}$ in the $\alpha \mathrm{Her}$ spectrum. In comparison, the curve obtained from an isothermal absorbing slab model at $2520 \mathrm{~K}$ (dashed line).

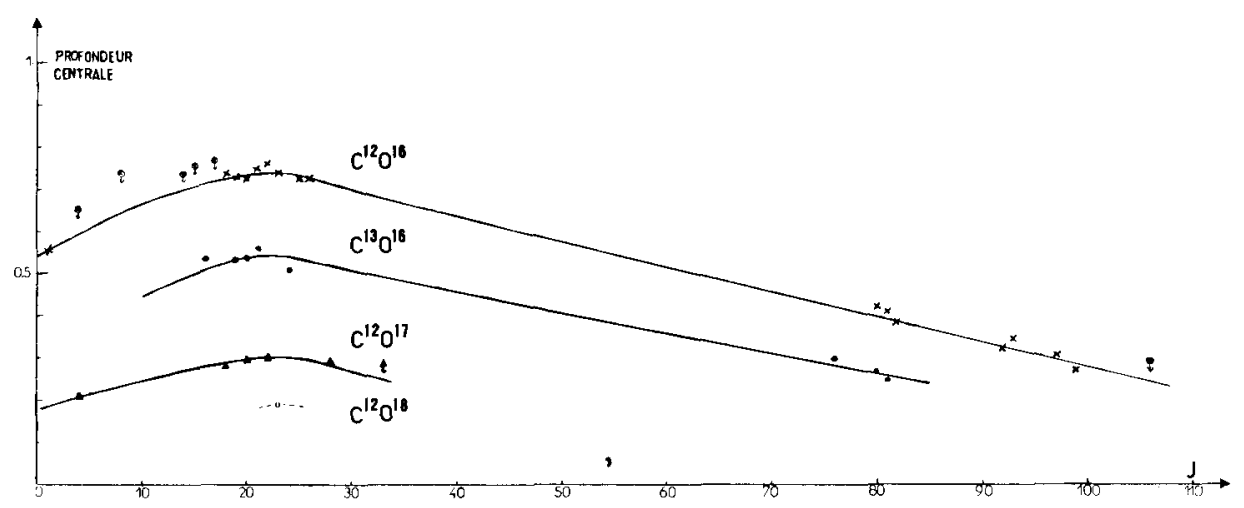

Fig. 10. Similar plot to Figure 9 but with the central line depths; the intensity of the continuum is taken equal to 1 . For both sets of curves (Figures 9 and 10) the large range without points is due to the effects of the folding of the $R 2-0$ branch, where it is impossible to find unblended lines. The points with an arrow indicate an upper limit for the equivalent width or the central depth and correspond to lines which are clearly partially blended.

variation of apparent central depth for the least blended single lines against rotational quantum number (Figure 10) a common maximum appears for $J$ around 24. It corresponds to an isothermal absorbing slab model a temperature: $T_{\mathrm{ex}} \simeq 2950 \mathrm{~K}$.

\subsection{Tentative estimation of ${ }^{12} \mathrm{C} /{ }^{13} \mathrm{C},{ }^{16} \mathrm{O} /{ }^{17} \mathrm{O},{ }^{16} \mathrm{O} /{ }^{18} \mathrm{O}$ ratios}

From an empirical method detailed by Fujita (1970) and suggested to me by T. Tsuji, based on use of lines of same intensity, we have determined a preliminary estimation of isotopic ratios. With the temperature discussed before we have obtained:

$$
\begin{aligned}
& { }^{12} \mathrm{C} /{ }^{13} \mathrm{C} \simeq 5.3 \pm 1 \\
& { }^{16} \mathrm{O} /{ }^{17} \mathrm{O} \simeq 450 \pm 50 \\
& { }^{16} \mathrm{O} /{ }^{18} \mathrm{O} \simeq 700 \pm 100
\end{aligned}
$$


An increase in accuracy could probably be obtained by using more sophisticated analysis. In first, temperature gradient must be taken into account.

The most interesting result is, without any doubt, the detection of ${ }^{17} \mathrm{O}$. This isotope has theoretically an essential role in the nucleosynthesis of the stars. It takes place in the $\mathrm{CNO}$ bi-cycle. As a consequence of the extreme temperature sensitivity of ${ }^{16} \mathrm{O} /{ }^{17} \mathrm{O}$ ratio, a further detailed analysis must be performed.

\section{Structure of the CO Atmosphere in R Leo}

There are special problems concerning Mira variables related to their changing spectrum. An analysis of $\mathrm{R}$ Leo is in progress and first results are presented. The two different spectra recorded at phase 0.23 and 0.85 during the same cycle show some evident difference visible from the low resolution spectra. In the first spectrum (Figure 11a) an unidentified molecular band (likely metallic oxyde) appears clearly in the $8000 \mathrm{~cm}^{-1}$ region. In the second spectrum (Figure $11 \mathrm{~b}$ ) at post minimum light, this band has disappeared. It is therefore a strongly phase-dependent band. On the other hand, emission in the Paschen lines of hydrogen are observable with $P_{\boldsymbol{\beta}}$ and $P_{\alpha}$. The both spectra have in common a large depression between $9200-9350 \mathrm{~cm}^{-1}$, like other M-type Mira variables, due to molecular bands.

The analysis from the high resolution spectrum of the 2-0 band of $\mathrm{CO}$ in the first spectrum (phase $=0.23$ ) shows an unexpected phenomenon, never related in molec-

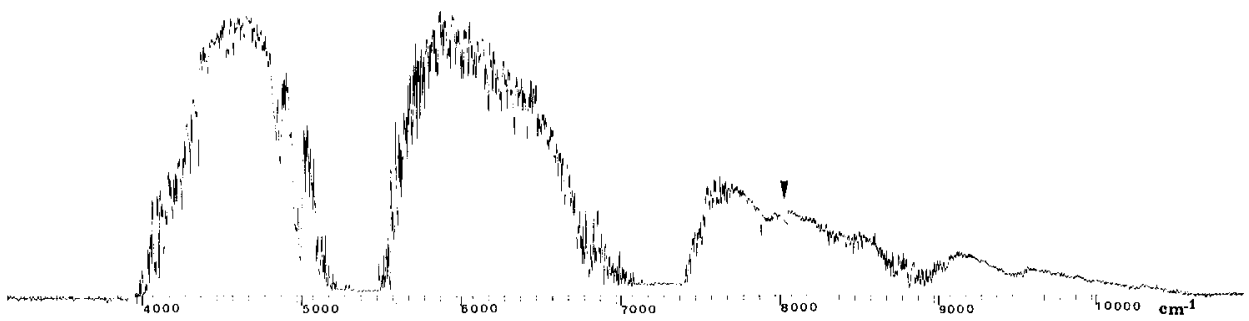

(a)

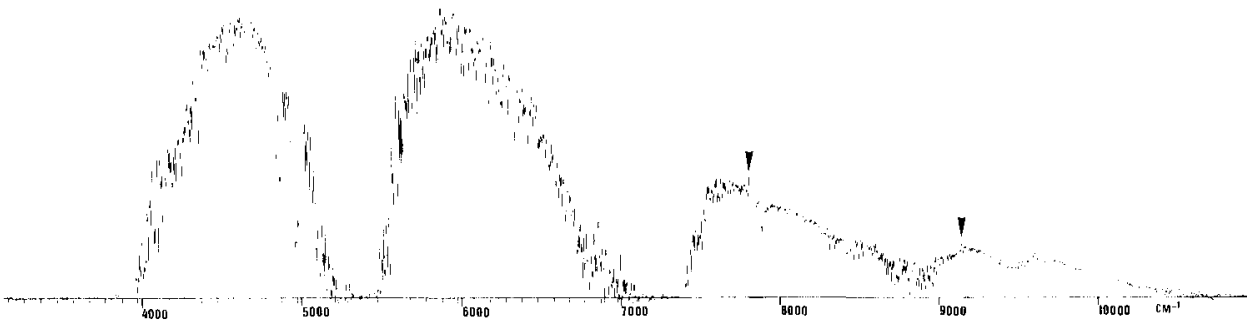

(b)

Fig. 11a-b. Low resolution spectra of $\mathbf{R}$ Leo at two different phases during the same cycle, showing some differences. At post-maximum light (Figure 11a) an absorption band in the $8000 \mathrm{~cm}^{-1}$ region appears. It has disappeared at post-minimum light (Figure 11b) and Paschen lines in emission are observable. 


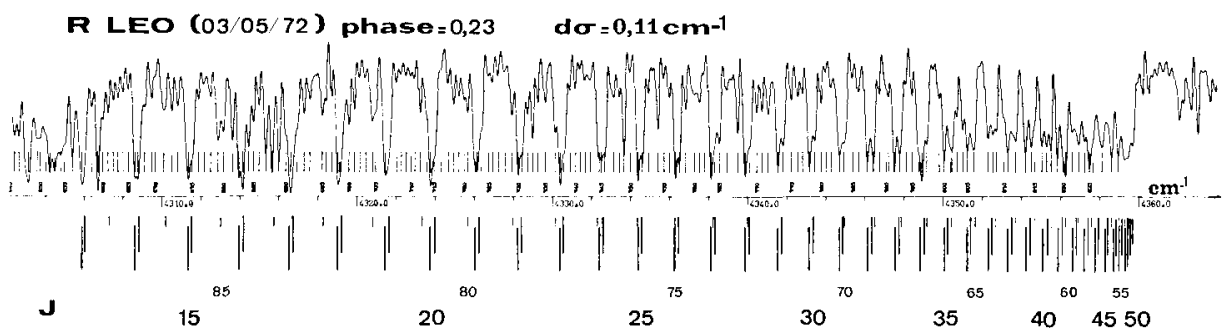

Fig. 12. Part of high resolution spectrum of $\mathrm{R}$ Leo in the $R 2-0$ branch region of ${ }^{12} \mathrm{C}^{16} \mathrm{O}$, showing the doubling of the low $J$ number lines. Both systems are schematically represented by series of dashes at different heights, below the spectrum. The smallest marks are for the high $J$ number lines.

ular features of Mira variables spectra. As it is shown in Figure $12 \mathrm{CO}$ band presents a line doubling. Below the spectrum are drawn the positions of each component for the $R$ 2-0 branch. But it must be noticed that the lines of high $J$ number, above about 50 are not distinguishable for a $\mathrm{CO}$ band while the corresponding components are very strong. This can be explained by the assumption of a stratified $\mathrm{CO}$ atmosphere with differentially expanding layers one being a cool layer and the other a hot layer.

We can also measure with accuracy from the well-defined doublets a difference of radial velocity of:

$$
12.8 \pm 0.1 \mathrm{~km} \mathrm{~s}^{-1}
$$

One CO layer seems moving at the same velocity as the star according to the Doppler shift computed by using radial heliocentric velocity of $\mathrm{R}$ Leo reported in Wilson's (1953) catalog, while the other layer, with strong high $J$ number lines is in expansion. The expanding layer seems to be hotter than the stable $\mathrm{CO}$ layer.

The atomic lines located in the same spectral region are not double.

A more complete analysis will be carried on, with a comparison with the second spectrum.

\section{Conclusion}

18 stars of $\mathrm{M}$ and $\mathrm{C}$ type have been observed at maximum resolution possible with the instrument employed. These spectra, which extend from 4000 to about $10000 \mathrm{~cm}^{-1}$ represent an enormous bulk of information. They provide the most powerful way for an accurate quantitative analysis of cool stars as has been illustrated here. But to be more effective laboratory work on molecules is urgently required in connection with advances in theoretical treatments of late-type star problems.

\section{References}

Boyce, P. B. and Sinton, W. M.: 1964, Astron. J. 69, 534.

Chauville, J., Querci, F., Connes, J., and Connes, P.: 1970, Astron. Astrophys. Suppl, $2,181$.

Connes, J., Connes, P., and Maillard, J.-P.: 1967, Coll. 'Méthodes Nouvelles de Spectroscopie Instrumentale', J. Phys. 28, C2. (English transl. in New Methods in Instrumental Spectroscopy, Gordon and Breach, 1972). 
Connes, J., Connes, P., Bouigue, R., Querci, F., Chauville J., and Querci M.: 1968, Ann. Astrophys 31, 485.

Frogel, J. and Hyland A.: 1972, Mem. Soc. Roy. Sci. Liège, 6th Ser. 3, 111.

Fujita, Y.: 1970, Interpretation of Spectra and Atmospheric Structure in Cool Stars, Univeristy Park Press.

Guelachvili, G. and Maillard J.-P.: 1970, Aspen International Conference on Fourier Spectroscopy. AFCRL Special Report No. 114, p. 151.

Johnson, H. L.: 1964, Bol. Obs. Tonantzintla Tacubaya 3, 305.

Johnson, H. L., Coleman, J., Mitchell, R. J., and Steinmetz, D. L.: 1968, Comm. Lunar Planetary Lab. 7, 83.

Kunde, V. G.: 1967, 'Tables of Theoretical Line Positions and Intensities of the $\Delta v=1, \Delta v=2, \Delta v=3$ Vibration-Rotation Bands of CO', NASA, X-622-67-248.

Lockwood, G. W. and Wing, R. F.: 1971, Astrophys. J. 169, 63.

Maillard, J.-P.: 1973, Thèse d'Etat, Université de Paris-Sud, No. 1157.

Mantz, A. W., Nichols, F. R., Alpert, B. D., and Rao ,V. N.: 1970, J. Mol. Spectrosc. 35, 325.

McCammon, D., Münch, G., and Neugebauer, G.: 1967, Astrophys. J. 147, 575.

Mertz, L.: 1972, Mem. Soc. Roy. Sci. Liège, 6th Ser. 3, 101.

Neugebauer, G. and Leighton, R.: 1969, 'Two-Micron Sky Survey - Preliminary Catalog', Caltech, Pasadena, Cal., NASA, Washington, D. C.

Querci, F.: 1974, this volume, p. 341.

Thompson, R. I., Johnson, H. L., Forbes, F. F., and Steinmetz, D. L.: 1972, Publ. Astron. Soc. Pacific 84, 775 and 779.

Wilson, R. E.: 1953, General Catalogue of Stellar Radial Velocities, Carnegie Institution of Washington, Washington, D.C., Pub. No. 601.

\section{DISCUSSION}

Hyland: Regarding $\mathrm{OH}$ lines do you actually see $\mathrm{OH}$ lines in the $2.8 \mu$ region or is it too cut out by the terrestrial atmosphere. If you do see any $\mathrm{OH}$ lines do these show the doubling that the $\mathrm{CO}$ lines do. Maillard: In R Leo they are strong and are not doubled.

Vardya: Going back to Dr Hyland's question I was wondering if one interprets this doubling of the $\mathrm{CO}$ line due to the two layers of the model having a different radial velocity. No; you are not finding it in $\mathrm{OH}$ now and maybe one has to think of some other interpretation. 